\section{Merging for strength}

MANY success stories have modest beginnings. Back in the mid-1970s - or so they like to tell it in Stockholm - a small Swedish venture capital company called Kabigen agreed to buy the airticket of a young Californian entrepreneur invited to Sweden to discuss collaboration on a joint research project.

The entrepreneur was Robert Swanson, then in the process of getting Genentech off the ground with Herbert Boyer of the University of California, San Francisco. Swanson had been invited to Sweden by the company's research director, Bertil Åberg, to discuss ways of applying genetic engineering techniques to a product for which the parent company, Kabi, had long been known: human growth hormone.

The research contract was one of the very first signed by Genentech. It resulted in the biosynthetic hormone Genotropin, which has since become a highly successful product; last year, Genotropin claimed 60 per cent of the world market outside the United States, with global sales of $\mathrm{SKr} 2.00$ billion ( $£ 200$ million).

The drug has, in the process, become the best seller for a new company, Kabi Pharmacia, formed in June 1990 when Kabi merged with Pharmacia to create what is now one of the largest pharmaceutical companies in Europe (and is itself a subsidary of a giant conglomerate, Procordia, put together under the chairmanship of Pehr Gyllenhammer, president of Volvo).

Like Kabi, Pharmacia has also had a long tradition of turning basic research carried out by university scientists into successful products. In the late $1960 \mathrm{~s}$, for example, the company, based in Uppsala, combined two lines of research at the nearby university - the discovery of immunoglobin $\mathrm{E}$ and the development of radioimmunoassay technology _ to develop a new technique for allergy testing.

The allergy test went on sale in 1974 . Seventeen years later, Kabi Pharmacia has a highly automated laboratory system that allows a simple blood test to be used to test for nearly 400 allergenic substances. This has enabled it to become the market leader in the field of allergy diagnostics, with annual sales of SKr 1.46 billion representing 70 per cent of the global market.

"There are many similar examples which demonstrate the importance of the close links which we have with the university community," says Ulf Lundkvist, director of research administration in the new company's corporate research and development department.

Indeed, the experience of the pharmaceutical industry in Sweden is often quoted as a paradigm of how an industry can benefit from links to basic research in the country's universities.

What shape these links will take in the future, however, remains to be seen. On the one hand, the new company has decided to align most of its research activities, both in-house and supported in universities, with the development of product lines with which it is already familiar. On the other, it is looking increasingly to research groups outside Sweden to provide the scientific inputs it requires to meet these strategic goals.

Both result from the pressures of international competition, which were themselves one of the main reasons for the merger between the two companies. "We intend to become a research-based international pharmaceutical company, and to have the muscle for long-term research you have to be a certain size; we were too small before," says Ola Rönn, corporate medical director.

The merger has given the joint company a substantial research base; its research and development budget last year was SKr1.4 billion ( $£ 140$ million), repre-

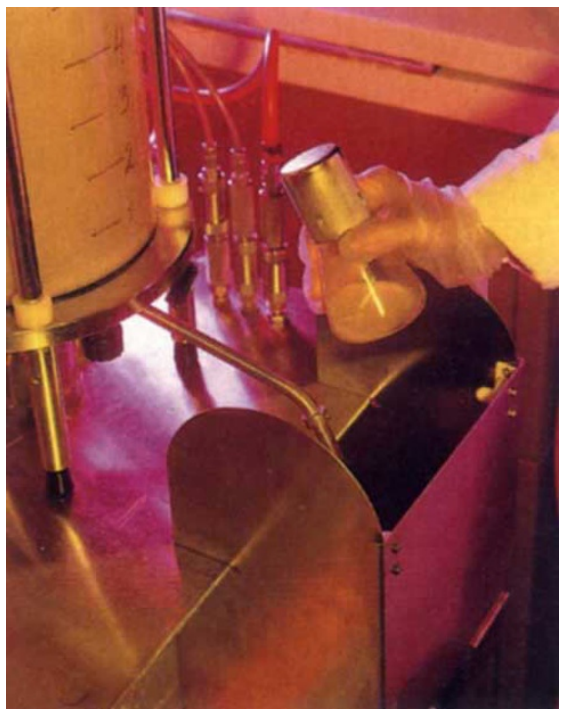

In-house research is now largely business-oriented.

senting 15 per cent of the company's sales. At the same time, the subsequent rationalization has resulted in the phasing out of what the company describes as "a number of miscellaneous projects and activities in the research area" in favour of a concentration of research on a limited number of strategic areas.

On the basis of successful products already on the market, the company has now decided to concentrate on six such areas: urology and gynaecology; oncology; growth and growth disorders (new insulin-like growth factor, which can be used in situations where there is an observed resistance to growth hormone); the treatment of blood clots and bleeding; cataract surgery and ophthalmic diseases; and anaesthesia.

Long-term research, especially in molecular biology, is being concentrated in a new Kabi Science Centre, a groupwide research organization based in Stockholm with a special focus on recombinant-DNA technology. This combines the operation of a newly formed Structural Biology Centre and molecular biology research in Kabigen.

The centre provides a central biotechnology resource for the whole of $\mathrm{Kabi}$ Pharmacia, specializing in genetic engineering, protein purification, protein engineering and cell culture. Like the rest of the company, it is now organizing much of its research around the six strategic objectives. "About 80 per cent of our research will be directed to the needs of our business units," says the centre's manager, Staffan Josephson.

According to Josephson, the company expects to remain heavily dependent on new ideas and techniques being developed in universities. "But in future, the decision to focus our research strategy means that in some areas we will probably be doing more [with universities], and others we may be doing less."

International competition in the research field will also lead to what Lundkvist describes as a "fundamental change" in the company's relationship with universities in Sweden, namely that they will have to be prepared to compete more than in the past for research contracts with research groups in foreign universities. "Now that we have this international presence focused on a relatively few research areas, we are looking for the best research groups worldwide," he says. Lundkvist points out that the company already has several international collaborations taking place outside Sweden, and expects this trend to continue.

Like many industrial research managers, Lundkvist says he is keen that the government should maintain an active role in helping to bring universities and industry closer together. In particular, the company supports moves by universities to develop internationally recognized centres of excellence. But he emphasizes the need for two-way communication to ensure that these centres respond to genuine industrial need.

"Industry is close to the market and has a lot of R\&D experience," says Lundqvist. There is therefore a need, for example, for universities to talk to industry to find out in which fields there will be most the greatest demand for PhDs in the future. "If the universities do not do this, with the free market that we will have in the new Europe, they will just end up educating good scientists who will then go and work in other countries." 